\title{
Coronary risk factor levels: Differences between educational groups in 1972-87 in eastern Finland
}

Juha Pekkanen, Antti Uutela, Tapani Valkonen, Erkki Vartiainen, Jaakko Tuomilehto, Pekka Puska

\begin{abstract}
Study objective - To compare differences in coronary heart disease (CHD) risk factor levels between educational groups in the 1970 s and 1980 s in eastern Finland. Design and participants-Independent, cross sectional population surveys were undertaken in 1972, 1977, 1982, and 1987 of randomly selected men and women aged 30-59 living in two provinces in eastern Finland. Altogether 20096 subjects participated. The lowest observed level of participation in either sex or province in any year was $77 \%$. Serum cholesterol values and blood pressure measurements, body mass index, smoking, and the level of education were determined in each survey using comparable methodology.
\end{abstract}

Main results - More poorly educated men and women had higher levels of all risk factors at the end of the study period (1987). There was no change between 1972 and 1987 in differences between educational groups in mean serum cholesterol values and the diastolic blood pressure level in either sex, and in smoking in men. In women, the proportion of smokers was highest in the better educated in the 1970 s but lowest in this group in the 1980s (interaction between year of examination and educational level p<0.01). Differences between educational groups in mean body mass index increased with time in both men $(p<0.001)$ and women $(p=0.06)$.

Conclusions - Relative differences between socioeconomic groups in CHD mortality have increased in Finland in the 1970 s and 1980s. Present results from eastern Finland show no reduction in differences between educational groups in risk factor levels, and even some evidence of increasing differences. Although a comparison between mortality trends and risk factor trends is problematic, trends in the risk factors analysed do not seem to be a major cause for the increasing differences in CHD mortality in Finland, at least in men. On the other hand, the risk factor trends analysed show no progress towards reducing inequalities in health, a major goal of public health policy.

(f Epidemiol Community Health 1995;49:144-149)

Coronary heart disease (CHD) mortality has declined among the middle aged population in most, though not all, industrialised countries. ${ }^{1}$
Finland has experienced a rapid decline in CHD mortality in both men and women since the end of $1960 \mathrm{~s}^{2}$ Although overall changes in CHD mortality in Finland have been favourable, the relative differences in mortality between socioeconomic groups have grown during the 1970 s and 1980 s. $^{34}$ There is evidence for similar developments in the 1970s in England $^{5}$ and in the United States. ${ }^{67}$

In Finland, ${ }^{348-10}$ as in most other industrialised countries, ${ }^{11}$ lower socioeconomic groups tend to have a more adverse coronary risk factor profile and a higher coronary mortality than higher socioeconomic groups. A significant part of the excess mortality in the lower socioeconomic groups may be due to the detrimental risk factor profile. ${ }^{91213}$ This suggests an avenue for diminishing socioeconomic differences in health according to the goals of health policy. ${ }^{14}$ However, there are a few reports from industrialised countries suggesting growing socioeconomic differences in the prevalence of cardiovascular risk factors, especially in smoking. ${ }^{15-20}$

This paper aimed to analyse changes in differences between educational groups in CHD risk factor levels among middle aged men and women in eastern Finland. An update of past analyses, ${ }^{34}$ on trends in differences between educational groups in CHD mortality among middle aged people in all of Finland is also presented.

\section{Methods}

MORTALITY DATA

Data on mortality in relation to level of education are based on the death records for the years 1971-91, which have been linked with the individual level records of the censuses carried out in Finland in 1970, 1975, 1980, and in $1985 .^{34}$ The computerised linkage of records was carried out by Statistics Finland by means of personal identification numbers used nationally. The data cover all deaths in Finland from coronary heart disease (ICD 410 414 ) in the age group 35 to 64 from 1971 to 1991. The age standardised death rates were calculated by the direct method using the 1966-70 stationary population of Finland as the standard population.

\section{RISK FACTOR DATA}

Cross sectional population surveys in 1972, 1977, 1982, and 1987 assessed the levels of coronary risk factors in the provinces of North Karelia and Kuopio in five year intervals. In 
Table 1 Age standardised mortality (per 100000) from coronary heart disease and number of deaths (in brackets) by years of education 1971-73, 1980-82, and 1989-91 for men and women aged 35 to 64 in all of Finland

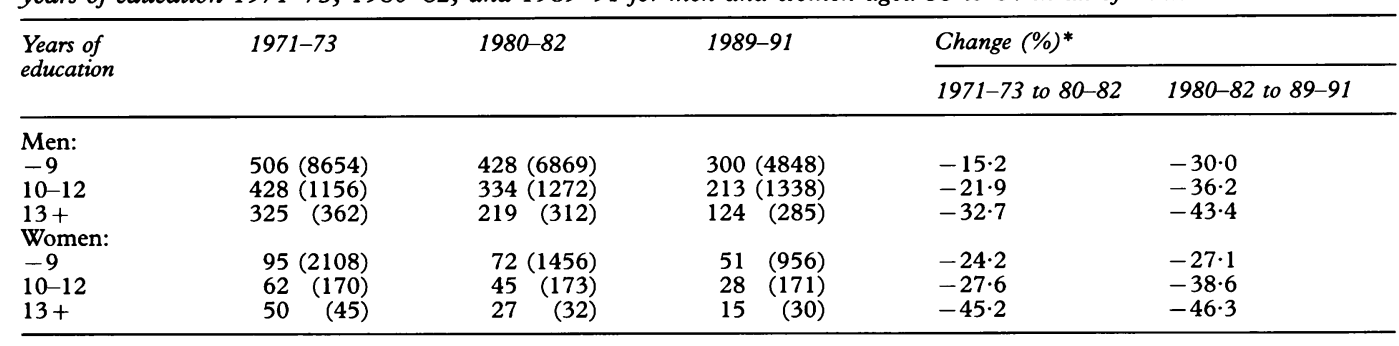

* Calculated from unrounded death rates

North Karelia, an intensive, community wide, multifactorial cardiovascular disease prevention programme began in $1972 .{ }^{21}$ For each survey, an independent random sample was drawn from the national population register. In the 1972 and the 1977 surveys, a random sample of $6.6 \%$ of the population born during 1913-47 was drawn in both areas. In 1982 and 1987, the sample included people aged 25-64 years. The samples were stratified so that at least 250 subjects of each sex and 10 year age group were chosen in each area. The common age range in all of the surveys was 30-59 years, the age range of risk factor data used in the present analyses.

The survey methods followed the WHO MONICA protocol in 1982 and $1987 . .^{22}$ Comparable methods were used in 1972 and 1977. The surveys included a self administered questionnaire, blood sampling, and measurements of height, weight, and blood pressure. Methods have been presented in detail elsewhere. ${ }^{21-23}$

Smoking was assessed in all surveys using exactly the same questionnaire. In the analyses, current smokers and those smokers who had quit smoking during the last half year were classified as smokers. Serum cholesterol was determined from frozen samples using the Liebermann-Burchard method in 1972 and 1977 , but in 1982 and 1987, serum cholesterol was determined from fresh sera using an enzymatic method (CHOD-PAP, Boehringer

Table 2 Number of those examined in relation to education level in men and women aged 30-59 in eastern Finland

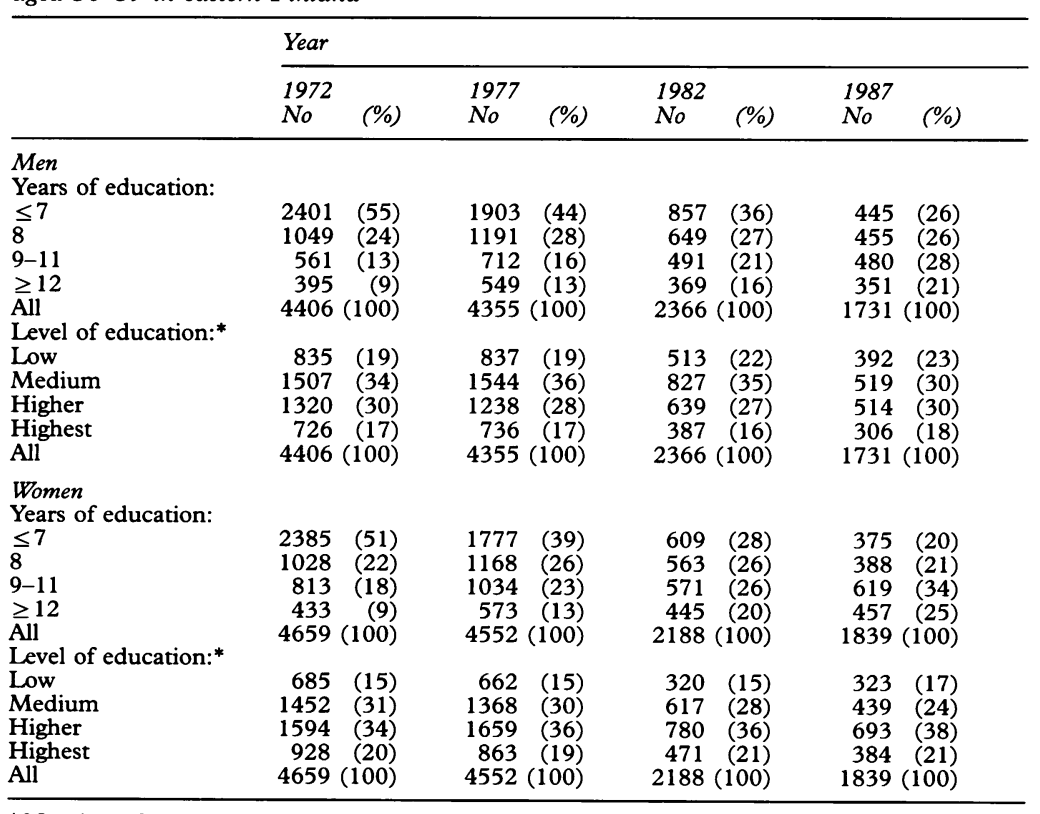

* Number of years of education relative to each person's five year birth cohort.
Mannheim, Monotest). The enzymatic assay method have $2 \cdot 4 \%$ lower values than the Liebermann-Burchard method. In 1972 and in 1977, blood pressure was measured with a shorter cuff bladder $(23 \mathrm{~cm})$ than in 1982 and in $1987(42 \mathrm{~cm})$. The longer cuff may give $4 \mathrm{mmHg}$ lower readings than the shorter cuff. ${ }^{24}$

Participation rates were very high, more than $90 \%$ in both areas and in both sexes in the first survey in 1972. The proportion participating decreased slightly over time, but remained still quite satisfactory. The lowest level of participation, $77 \%$ was observed among men in North Karelia in $1982 .{ }^{23}$

Years of education was always investigated with the same question: "How many years have you had school altogether or studied full time in your life?" The average number of years spent in full time education has increased significantly during the past 20 years in Finland. Therefore, in order to obtain groups of comparable size in different study years, each five year birth cohort, men and women included, was divided into four educational categories. In the study population, years of birth ranged from 1913 to 1957 , so there were nine five year birth cohorts. For each cohort, the mode for the years of education was determined. The

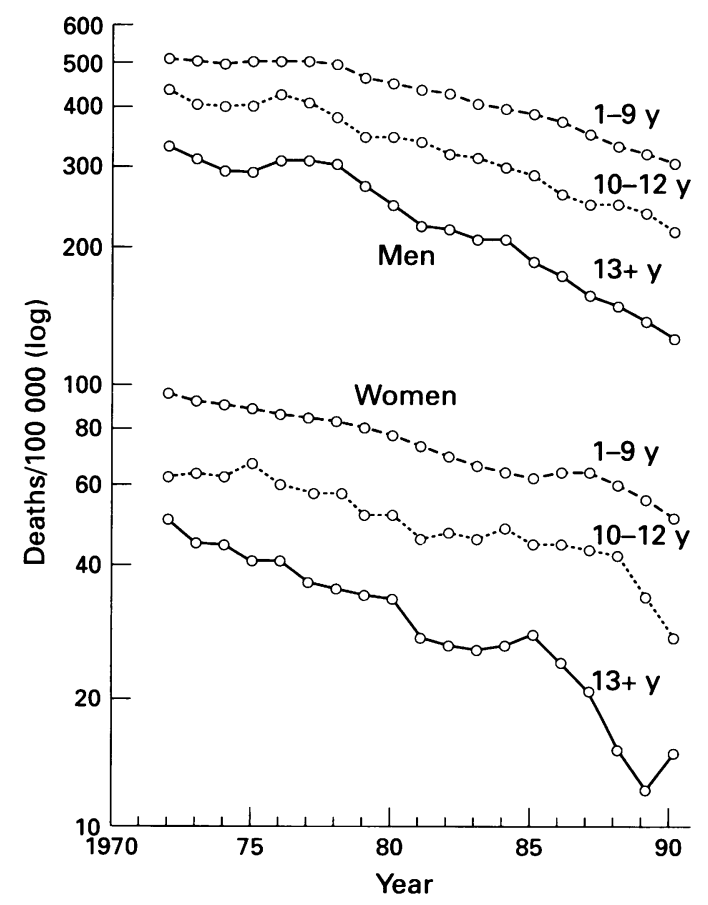

Figure 1 Age standardised coronary heart disease mortality (per 100000) in 1971-91 in relation to years of education in men and women aged 35-64 in all of Finland. (Three year moving averages.) 
Table 3 Average coronary risk factor values in relation to level of education in different years from men aged 30-59 in eastern Finland

\begin{tabular}{|c|c|c|c|c|}
\hline Risk factor/Level of education* & 1972 & 1977 & 1982 & 1987 \\
\hline \multicolumn{5}{|c|}{ Mean serum cholesterol $(\mathrm{mmol} / \mathrm{l}) \dagger$ : } \\
\hline Low & $7 \cdot 04$ & $6 \cdot 87$ & $6 \cdot 32$ & $6 \cdot 33$ \\
\hline Medium & $7 \cdot 04$ & $6 \cdot 81$ & $6 \cdot 31$ & $6 \cdot 27$ \\
\hline Higher & $6 \cdot 92$ & $6 \cdot 67$ & $6 \cdot 27$ & $6 \cdot 19$ \\
\hline Highest & $6 \cdot 71$ & $6 \cdot 47$ & $6 \cdot 12$ & 5.98 \\
\hline (No) & $(4210)$ & (4317) & (2365) & (1659) \\
\hline \multicolumn{5}{|c|}{ Mean diastolic blood pressure $(\mathrm{mmHg})+$ : } \\
\hline Low & $92 \cdot 2$ & $90 \cdot 9$ & $88 \cdot 2$ & $89 \cdot 6$ \\
\hline Medium & $92 \cdot \overline{9}$ & $90 \cdot 7$ & $87 \cdot 3$ & $88 \cdot 4$ \\
\hline Higher & $92 \cdot 6$ & $89 \cdot 8$ & $87 \cdot 0$ & $88 \cdot 0$ \\
\hline Highest & $92 \cdot 2$ & $89 \cdot 5$ & $86 \cdot 7$ & $87 \cdot 2$ \\
\hline (No) & (4218) & (4325) & (2364) & $(1660)$ \\
\hline \multicolumn{5}{|l|}{ Proportion smokers $(\%) \dagger:$} \\
\hline Low & $58 \cdot 1$ & $48 \cdot 7$ & $42 \cdot 7$ & $39 \cdot 3$ \\
\hline Medium & $51 \cdot 6$ & $45 \cdot 6$ & $38 \cdot 9$ & $39 \cdot 6$ \\
\hline Higher & $46 \cdot 5$ & $41 \cdot 9$ & $37 \cdot 0$ & $34 \cdot 7$ \\
\hline Highest & $45 \cdot 3$ & $38 \cdot 1$ & $34 \cdot 4$ & $29 \cdot 6$ \\
\hline (No) & (4337) & (4273) & $(2340)$ & $(1720)$ \\
\hline \multicolumn{5}{|l|}{ Mean body mass index $\left(\mathrm{kg} / \mathrm{m}^{2}\right) \ddagger$ : } \\
\hline Low & $25 \cdot 7$ & $26 \cdot 2$ & $26 \cdot 9$ & $27 \cdot 4$ \\
\hline Medium & $26 \cdot 1$ & $26 \cdot 4$ & $26 \cdot 6$ & $27 \cdot 1$ \\
\hline Higher & $26 \cdot 0$ & $25 \cdot 9$ & $26 \cdot 3$ & $26 \cdot 7$ \\
\hline Highest & $25 \cdot 8$ & $26 \cdot 0$ & $26 \cdot 0$ & $26 \cdot 4$ \\
\hline (No) & $(4222)$ & $(4325)$ & (2365) & (1695) \\
\hline
\end{tabular}

* Number of years of education relative to each person's five year birth cohort.

t When adjusting for age and study area, terms for year and level of education significan $(p<0.001)$ and interaction between year and level of education not significant $(p>0.5)$.

$\neq$ When adjusting for age and study area, terms for year and level of education significan $(p<0.001)$ and interaction between year and level of education significant $(p=0.001)$.

mode years for the birth cohorts were, from the oldest cohort to the youngest, $4,4,6,6$, $8,8,8,8$, and 10 years. People who had as many years of education as the mode formed what we called the "medium" education category. Those with less education than the medium group belonged to the "low" education group. People in the highest quantile of education formed the "highest" education group. The remaining subjects were called "higher" education group. However, results were also analysed using the absolute cut points shown in table 1 . The conclusions from these analyses were identical to those presented.

Differences in risk factor levels between educational groups were analysed using logistic regression models for categorical variables and analysis of covariance for continuous variables. A binary variable was used in the logistic re-

Table 4 Average coronary risk factor values in relation to level of education in different years for women aged 30-59 in eastern Finland

\begin{tabular}{|c|c|c|c|c|}
\hline Risk factor/Level of education* & 1972 & 1977 & 1982 & 1987 \\
\hline \multicolumn{5}{|c|}{ Mean serum cholesterol $(\mathrm{mmol} / \mathrm{l}) \dagger$ : } \\
\hline Low & 6.99 & $6 \cdot 65$ & $6 \cdot 27$ & $6 \cdot 10$ \\
\hline Medium & 6.93 & $6 \cdot 56$ & $6 \cdot 14$ & $6 \cdot 01$ \\
\hline Higher & $6 \cdot 90$ & $6 \cdot 52$ & $6 \cdot 08$ & $5 \cdot 85$ \\
\hline Highest & $6 \cdot 72$ & $6 \cdot 35$ & $5 \cdot 85$ & $5 \cdot 78$ \\
\hline (No) & (4432) & $(4502)$ & $(2184)$ & \\
\hline \multicolumn{5}{|c|}{ Mean diastolic blood pressure $(\mathrm{mmHg}) \mathrm{t}$ : } \\
\hline Low & $92 \cdot 6$ & $88 \cdot 2$ & $84 \cdot 7$ & $84 \cdot 3$ \\
\hline Medium & $91 \cdot 8$ & $87 \cdot 4$ & $83 \cdot 5$ & $83 \cdot 4$ \\
\hline Higher & $91 \cdot 9$ & $87 \cdot 1$ & 83.9 & $82 \cdot 7$ \\
\hline Highest & $90 \cdot 4$ & $85 \cdot 8$ & $83 \cdot 6$ & $81 \cdot 7$ \\
\hline (No) & $(4450)$ & $(4537)$ & (2183) & (1783) \\
\hline \multicolumn{5}{|l|}{ Proportion smokers (\%)‡: } \\
\hline Low & $8 \cdot 2$ & $12 \cdot 0$ & $14 \cdot 4$ & $21 \cdot 3$ \\
\hline Medium & $8 \cdot 3$ & $11 \cdot 2$ & $16 \cdot 7$ & $18 \cdot 8$ \\
\hline Higher & $10 \cdot 3$ & $9 \cdot 4$ & $14 \cdot 8$ & $13 \cdot 3$ \\
\hline Highest & $15 \cdot 5$ & $12 \cdot 8$ & $12 \cdot 8$ & $12 \cdot 1$ \\
\hline (No) & $(4581)$ & $(4520)$ & $(2155)$ & (1822) \\
\hline \multicolumn{5}{|l|}{ Mean body mass index $\left(\mathrm{kg} / \mathrm{m}^{2}\right) \S:$} \\
\hline Low & $27 \cdot 3$ & $27 \cdot 0$ & $27 \cdot 3$ & $27 \cdot 4$ \\
\hline Medium & $27 \cdot 2$ & $26 \cdot 8$ & $26 \cdot 1$ & $26 \cdot 7$ \\
\hline Higher & $26 \cdot 6$ & $26 \cdot 1$ & $26 \cdot 0$ & $26 \cdot 1$ \\
\hline Highest & $25 \cdot 9$ & $25 \cdot 3$ & $\begin{array}{l}24 \cdot 9 \\
(2188)\end{array}$ & $\begin{array}{l}25 \cdot 1 \\
(1782)\end{array}$ \\
\hline
\end{tabular}

* Number of years of education relative to each person's five year birth cohort.

+ When adjusting for age and study area, terms for year and level of education significan $(p<0.001)$ and interaction between year and level of education not significant $(p>0.05)$.

$\neq$ When adjusting for age and study area, terms for year and level of education not significan $(p>0.05)$ and interaction between year and level of education significant $(p<0.01)$

When adjusting for age and study area, terms for year and level of education significan $(p<0.001)$ and interaction between year and level of education marginally significant $(p=0.06)$ gression analysis for "smoking". No trend tests were used; education was always treated as a categorical variable with three degrees of freedom $(\mathrm{df}=3)$. All models used included year of examination, living area, and age. Socioeconomic differences in risk factor trends were tested into the model an interaction term between education and year of examination $(\mathrm{df}=9)$.

There are significant differences between the two study areas in risk factor levels. ${ }^{23}$ Because of this the analyses were first done for the two areas separately. The conclusions from these analyses were the same as those presented here. In addition, no statistically significant difference between the two study areas in changes in differences between educational groups for risk factor levels was seen. Because of this the regional results are not presented here.

\section{Results}

Although CHD mortality has declined in all educational groups in Finland, the relative decline has been faster among highly educated men and women (table 1, fig 1). The absolute differences between educational groups have, however, stayed stable.

The average number of years spent in full time education increased rapidly after 1972, when the first surveys were carried out in eastern Finland (table 2). A relative classification within each person's five year birth cohort was therefore used. Most risk factors were higher in more poorly educated than in better educated men and women during the whole study period (tables 3 and 4, figs 2 and 3). The only exception is smoking among women and body mass index among men during the 1970s. Differences between educational groups in mean serum cholesterol and diastolic blood pressure did not change statistically significantly in the period 1972-87 in either men or women. However, there was some suggestion of an increase during the last five year period, especially in men. The only significant educational difference in trends in men was the divergence of the mean body mass index trends (table 3, fig 2). In 1972, the least educated men tended to have the lowest mean body mass index. However, due to the rapid increase in body mass index in this group, in 1987 it had the highest body mass index levels.

In 1972, the best educated women had the highest prevalence of smoking (table 4, fig 3). Since then smoking has declined somewhat in this group, but it has increased in all other groups, so that the association between education and smoking has changed direction. As in men, differences between educational groups in obesity have also tended to increase among women $(p=0.06)$.

Figure 1 shows increases only in the relative differences in mortality between educational groups. In contrast, the statistical tests in tables 3 and 4 compare absolute differences in serum cholesterol, diastolic blood pressure, and body mass index, but relative differences in the proportion of smokers. Comparing changes in the relative differences in serum cholesterol, diastolic blood pressure, and body mass index 


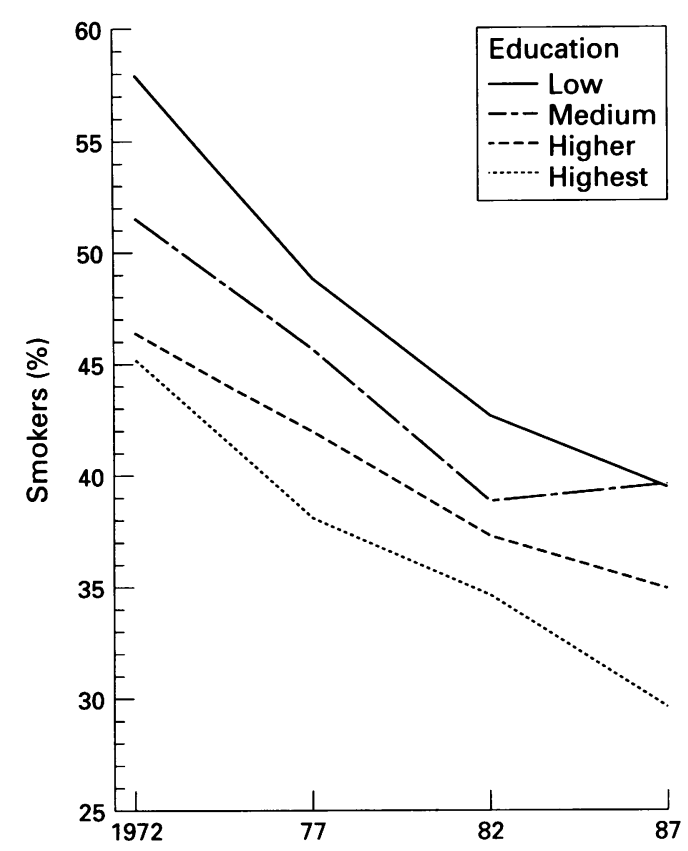

Men
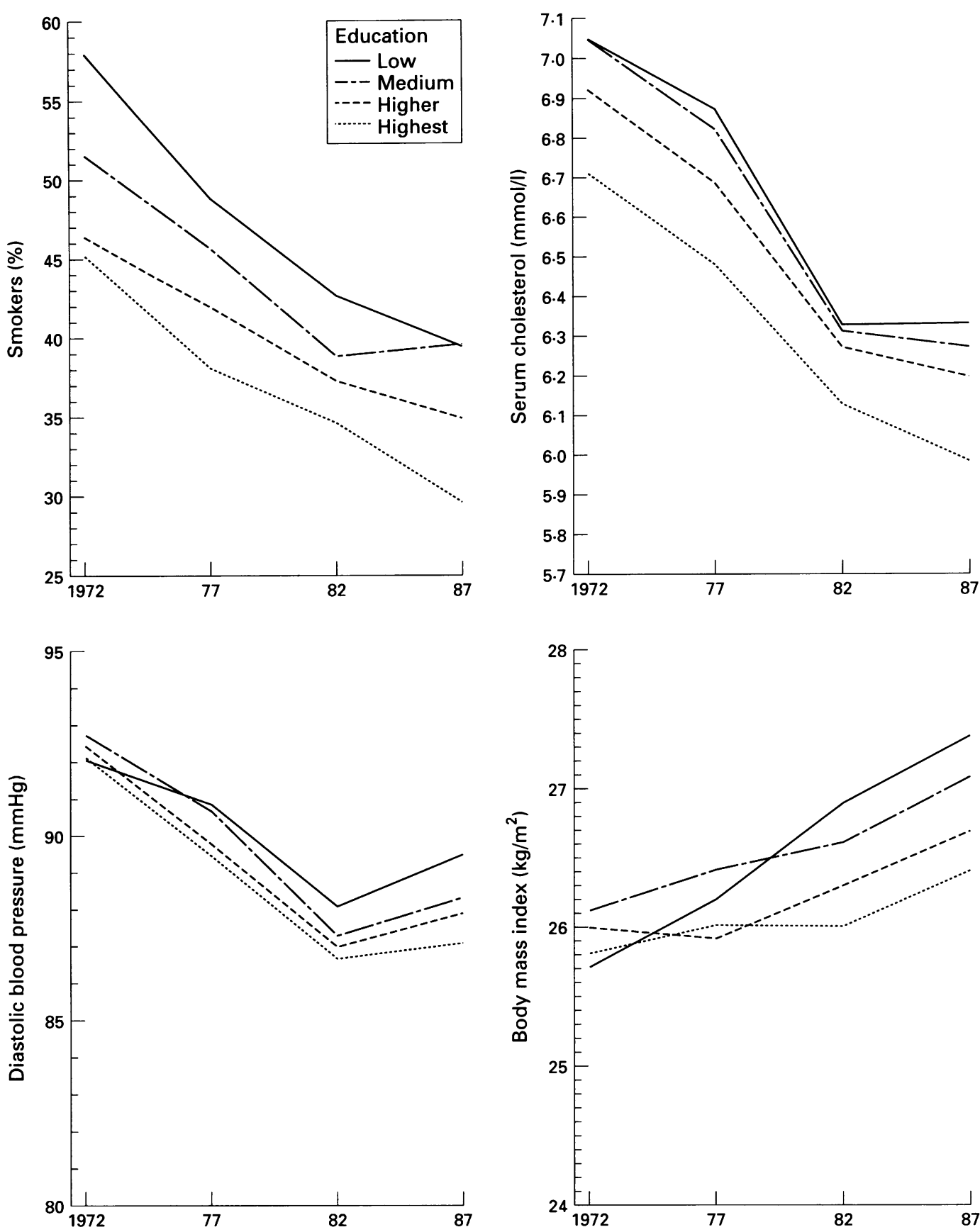

Figure 2 Age standardised cardiovascular risk factor levels in relation to level of education in eastern Finnish men aged 30-59 in 1972-87. Note the difference between men and women in the scaling of the figures on smoking.

between educational groups does not, however, change the conclusions. Men in the lowest educational group in 1972 had a $4.9 \%$ and in 1987 a $5.9 \%$ higher mean serum cholesterol concentration than men in the highest educational group. The respective percentages in women were $4.0 \%$ in 1972 and $5.5 \%$ in 1987 . These differences are not statistically significant ( $p>0.5$ for the interaction between year of examination and education using logarithmic transformation of serum cholesterol).

\section{Discussion}

Finland has experienced a considerable decline in CHD mortality in the past 20 years. Even after this decline, however, male CHD mortality in Finland, especially in eastern Finland, is still among the highest in the world. ${ }^{25}$ Average levels of many classic CHD risk factors seem to have declined in Finland since the middle of the 1960s. ${ }^{22326}$ Although changes have generally been favourable, relative differences in CHD mortality between educational groups have increased in Finland. The present study suggests that some increases in the differences between educational groups in risk factor levels have also taken place in eastern Finland.

In this study, smoking was always assessed with the same questionnaire. Serum cholesterol was determined from frozen samples using the Liebermann-Burchard method in 1972 and 1977, but in 1982 and 1987 fresh sera and an enzymatic method were used. In addition, in 1972 and 1977 blood pressure was measured with a shorter cuff than in 1982 and in 1987. These changes in methodology cause some 
Women
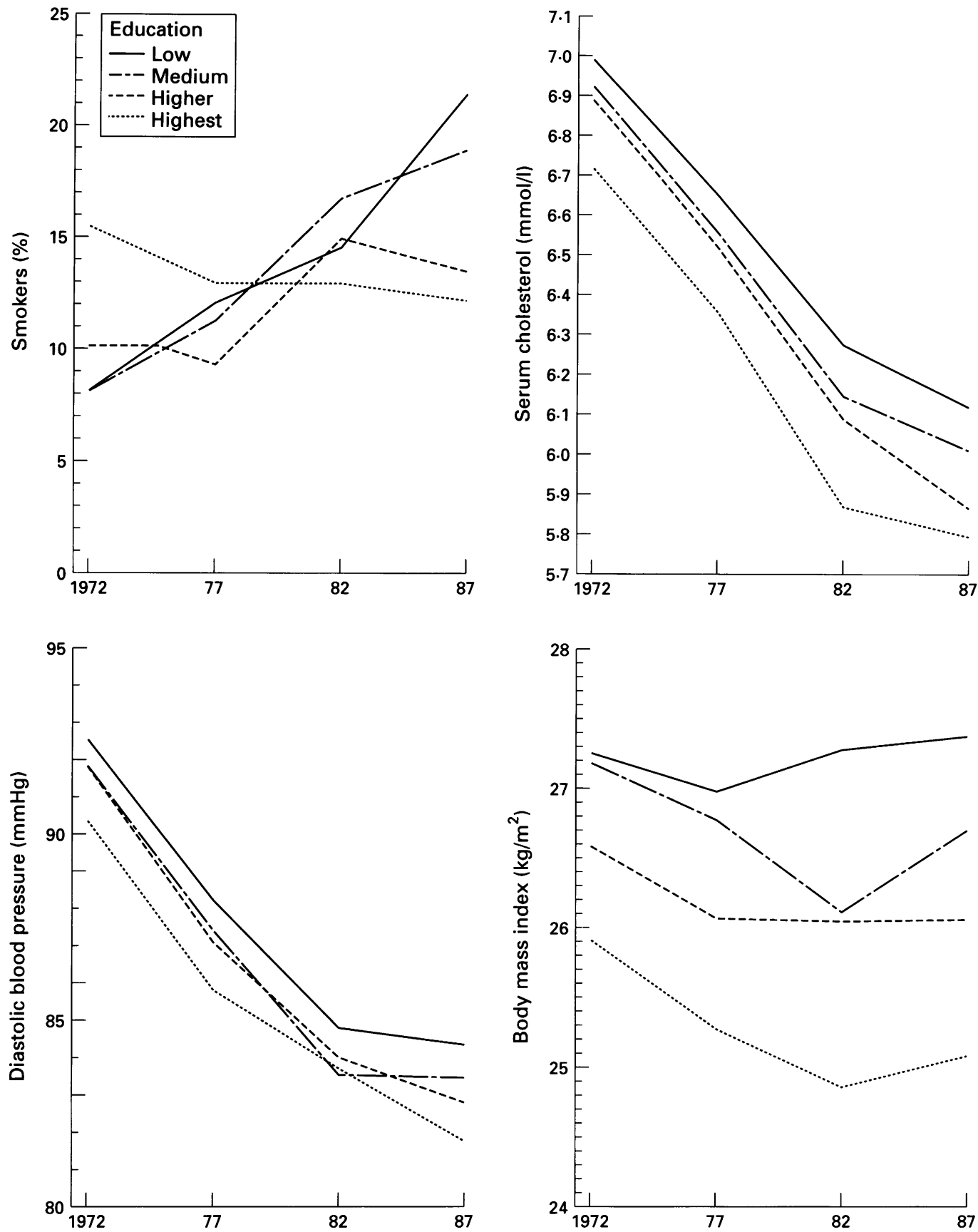

Figure 3 Age standardised cardiovascular risk factor levels in relation to level of education in eastern Finnish women aged 30-59 in 1972-87. Note the difference between men and women in the scaling of the figures on smoking.

difficulty in comparisons between the risk factor levels in the 1977 and 1982 surveys, but they have little effect on the comparisons of educational differences between surveys.

The present analyses show that relative differences in CHD mortality between educational groups widened in the 1970 s and 1980s. The findings are similar when using occupation instead of education in the analyses. $^{34}$ There is evidence for a corresponding development in England during the $1970 s^{5}$ In the USA, differences between educational groups in all cause mortality seem to have increased between 1970 and $1986 .^{7}$ In addition, differences in CHD mortality between communities with differing occupational structures increased in the USA between 1968 and $1982 .{ }^{6}$
In most industrialised countries, ${ }^{8911}$ lower socioeconomic groups tend to have a more adverse cardiovascular risk factor profile. A significant part of the association between socioeconomic status and CHD mortality is mediated through the known, preventable risk factors in Finland, ${ }^{912}$ as in many other industrialised countries. ${ }^{13}$ There are a few previous reports that suggest growing socioeconomic differences in the prevalence of some cardiovascular risk factors. Two reports from the USA, ${ }^{1516}$ and one from Sweden, ${ }^{17}$ showed growing socioeconomic differences in the prevalence of smoking, and a report from the USA suggested growing differences in the mean serum cholesterol level too. ${ }^{18}$ Reports on obesity have given mixed results. ${ }^{190}$

In these analyses, there was an increase in 
differences between educational groups in body mass index among both sexes and in the prevalence of smoking among women. With regard to the mean serum cholesterol concentration and diastolic blood pressure level, no change in differences between educational groups was observed overtime. A direct comparison between the risk factor trends and the mortality trends was not possible, as the former concerns eastern Finland only and the latter the country as a whole. If the national changes in differences between educational groups with regard to risk factor levels have been similar to those found in these analyses, the diverging trends in smoking may have contributed to the diverging trends in CHD mortality among women. However, smoking has increased mainly in the younger age groups, ${ }^{27}$ and it may not yet have a strong affect on mortality. The significance of the diverging trends in mean body mass index is, in contrast, unclear. Several studies have suggested that body mass index is not an independent risk factor for CHD, when adjusting for smoking, serum cholesterol, and blood pressure.$^{28}$ Results are, however, conflicting. ${ }^{29}$ Nor is it obvious which is cause and which effect low education or high body mass index. ${ }^{30}$ The relation is probably bidirectional, and may even be confounded by other factors such as heredity. ${ }^{31}$ Without concomitant increases in differences between educational groups in serum cholesterol, diastolic blood pressure, and smoking among men, the possible effect of the diverging trends in body mass index on the diverging mortality trends is probably small. The increasing differences between educational groups in both body mass index and CHD mortality may partly reflect increasing differences in other factors such as physical activity, nutritional changes not reflected in the serum cholesterol level, and the use of alcohol.

In contrast to the goals of health policy, ${ }^{14}$ trends in CHD mortality in Finland have been less favourable among the lower socioeconomic groups compared with higher groups. ${ }^{3410}$ Nor was there any evidence for diminishing differences in risk factor levels between educational groups in our analyses, and even some evidence for increasing differences. Although a direct comparison between mortality trends and risk factor trends is problematic, the observed increases in differences in risk factor levels seem too limited to explain the increasing differences in CHD mortality, at least among men. On the other hand, the risk factor trends analysed show no progress towards reducing inequalities in health, a second major goal of public health policy. To decrease the health inequalities between socioeconomic groups, present health education methods should be re-evaluated and reformulated to take into account the needs of the lower social classes. This by itself will probably not be sufficient, but the increasing health inequalities need to be addressed at several levels, from general social policy to everyday practice, to form a wider and more effective programme of health promotion. ${ }^{11}$

1 Thom TJ. International mortality from heart disease: rates and trends. Int $\mathcal{F}$ Epidemiol 1989;18(suppl 1):S20-8. 2 Pyörälä K, Salonen JT, Valkonen T. Trends in coronary heart disease mortality and morbidity and related factors in Finland. Cardiology 1985;72:35-51.

3 Valkonen T, Martelin T, Rimpelä A. Socio-economic mortality differences in Finland 1971-85. Helsinki: Statistics Finland, 1990. Studies 176.

4 Valkonen T, Martelin T, Rimpelä A, Notkola V, Savela S. Socio-economic mortality differences in Finland 1981-90. Socio-economic mortality differences in Finland 198

5 Marmot MG, McDowell ME. Mortality decline and widenMarmot MG, McDowell ME. Mortality decline

6 Wing S, Dargent-Molina P, Casper M, Riggan W, Hayes CG Tyroler HA. Changing association between community occupational structure and ischaemic heart disease mortality in the United States. Lancet 1987;ii:1067-70.

7 Pappas G, Queen S, Hadden W, Fisher G. The increasing disparity in mortality between socioeconomic groups in the United States, 1960 and 1986. N Engl F Med 1993; 329:103-9.

8 Tuomilehto J, Puska P, Virtamo J, Neittaanmäki L, Koskela $\mathrm{K}$. Coronary risk factors and socioeconomic status in Eastern Finland. Prev Med 1978;7:539-49.

9 Pekkanen J, Tuomilehto J, Uutela A, Vartiainen E, Nissinen A. Social class, coronary risk factors, and mortality among eastern Finnish men and women (in Finnish). Duodecim 1992;108:1395-402.

10 Valkonen $T$. Trends in regional and socio-economic mortality differentials in Finland. International fournal of Health Sciences 1992;3:157-66.

11 Adler NE, Boyce WT, Chesney MA, Folkman S, Syme SL. Socioeconomic inequalities in health. No easy solution. fAMA 1993;269:3140-5.

12 Salonen JT. Socioeconomic status and risk of cancer, cerebral stroke, and death due to coronary heart disease and any disease: A longitudinal study in Eastern Finland. $\mathcal{f}$ Epidemiol Community Health 1982;36:294-7.

13 Marmot MG, Shipley MJ, Rose G. Inequalities in death specific explanations of a general pattern? Lancet 1984; 1003-6.

14 World Health Organization Regional Office for Europe. Targets for health for all. Copenhagen: WHO, 1985.

15 Pierce JP, Fiore MC, Novotny TE, Hatziandreu EJ, Davis RM. Trends in cigarette smoking in the United States. JAMA 1989;261:56-60.

16 Covey LS, Zanf EA, Wynder EL. Cigarette smoking and occupational status: 1977 to 1990 . Am f Public Health 1992;82:1230-4.

17 Rosén $M$, Hanning $M$, Wall S. Changing smoking habits in Sweden: Towards better health, but not for all. Int $\mathfrak{f}$ Epidemiol 1990;19:316-22.

18 National Center for Health Statistics. Trends in serum cholesterol levels among US adults aged 20 to 74 years. fAMA 1987;257:937-42.

19 Flenagan KM, Harlan WR, Landis JR. Secular trends in body mass index and skinfold thickness with socioeconomic factors in young adult men. Am 7 Clin Nutr 1988;48:544-51.

20 Kuskowska-Wolk A, Bergström R. Trends in body mass index and prevalence of obesity in Swedish men 1980-89. $f$ Epidemiol Community Health 1993;47:103-8.

21 Puska P, Nissinen A, Tuomilehto J, et al. The communitybased strategy to prevent coronary heart disease: Conclusions from the ten years of the North Karelia project. Ann Rev Public Health 1985;6:147-93.

22 WHO MONICA Project (prepared by Tunstall-Pedoe $H$. .). The World Health Organization MONICA project (monitoring trends and determinants in cardiovascular disease): major international collaboration. $\mathcal{f}$ Clin Epidemiol 1988; 41:105-14.

23 Vartiainen E, Korhonen HJ, Pietinen P, et al. Fifteen-year trends in coronary risk factors in Finland, with special reference to North Carelia. Int f Epidemiol 1991;20:65162.

24 Nissinen A, Tuomilehto J, Korhonen HJ, et al. Ten-year results of hypertension care in the community. Follow-up of the North Karelia hypertension control program. Am of the North Karelia hypertensi

25 WHO MONICA project (prepared by Tuomilehto J, Kuulasmaa K, Torppa J) Geographic variation in mortality from cardiovascular diseases. Baseline data on selected population characteristics and cardiovascular mortality. World Health Stat $Q$ 1987;40:171-84.

26 Pekkanen J. Coronary heart disease during a 25-year followup. Risk factors and their secular trends in the Finnish cohorts of the seven countries study. Helsinki: Government Printing Centre, 1987. Academic dissertation. Health Services search by the National Board of Health in Finland no 45 .

27 Vartiainen E, Puska P, Koskela K, Nissinen A, Tuomilehto J. Ten-year results of a community-based anti-smoking program (as part of the North Karelia project in Finland).
. Ten-year results of a community-based anti-smoking program (as part of the North Karelia proje

28 Shaper AG, Pocock SJ, Walker M, Phillips AN, Whitehead TP, MacFarlane PW. Risk factors for ischaemic heart disease: the prospective phase of the British Regional Heart Study. $\mathcal{F}$ Epidemiol Community Health 1985;39: 197-209.

29 Jarrett RJ. Is there an ideal body weight? $B M F$ 1986;293: 493-5.

30 Gortmaker SL, Must A, Perrin JM, Sobol AM, Dietz WH. Social and economic consequences of overweight in adolescence and young adulthood. $N$ Engl f Med 1993;329: 1008-12.

31 Stunkard AJ, Sorensen TIA. Obesity and socioeconomic status - a complex relation. N Engl f Med 1993;329: 1036-7. 